\title{
The Effects of Type II Diabetes Mellitus on Renal Parameters with Hypertensive Patients: Comparative Study
}

\section{Hipertansif Hastalarda Tip II Diabetes Mellitusun Renal Parametreler Üzerine Etkisi: Karşılaştırmalı Bir Çalışma}

Hamza Aslanhan $*^{1}$, Ahmet Yllmaz ${ }^{1}$

ÖZET

Amaç: Diabetes mellitus ve hipertansiyon, toplumda yaygın olarak görülen iki hastalık grubu olup bir çok sistemi etkileyerek, mortalite ve morbiditeyi arttırmaktadır. Bu çalışmanın amacı, hipertansiyon ile hipertansiyona ek olarak Tip 2 diabetes mellitus tanısı olan hastaların, renal fonksiyonlarının incelenmesi ve bu hastalıkların böbrek üzerindeki etkilerinin karşılaştırılarak değerlendirilmesidir. Yöntem: Çalışmaya, İstanbul Eğitim Araştırma Hastanesi dahiliye ve diyabet polikliniklerinde ayaktan takip edilen, 35-70 yaşları arasında 85 hipertansiyon, 85 Tip 2 diabetes mellitus ve hipertansiyon tanılı, toplam 170 adet hasta arşiv dosyaları retrospektif olarak taranarak dahil edildi. Her iki gruptan, klinik bulgular ve demografik özellikler taranarak kayıt edildi. Bulgular: Tip 2 diabetes mellitus ve hipertansiyon grubunda, albüminüri oranı $(\% 30,6)$, hipertansiyon grubundan $(\% 16,5)$ anlamlı olarak daha yüksekti ( $\mathrm{p}=0,047)$. Glomerüler filtrasyon hızı $<60 \mathrm{~mL} / \mathrm{dk} / 1,73 \mathrm{~m}^{2}$ olanların oranı açısından hipertansiyon grubu ile $(\% 2,4)$ Tip 2 diabetes mellitus ve hipertansiyon grubu (\%5,9) arasında anlamlı farklılık yoktu $(\mathrm{p}=0,44)$. Sonuç: Tip 2 diabetes mellitus; hipertansiyon hastalarında albüminüriyi arttırmaktadır. Bu durum, böbrek yetmezliğine hızlı gidişin bir görüntüsü olabilir.

Anahtar kelimeler: Hipertansiyon, tip 2 Diabetes Mellitus, böbrek hastalığı

\section{ABSTRACT}

Objective: Hypertension and diabetes mellitus are two groups of diseases common in society and increase the morbidity and mortality by affecting many systems. The aim of this study is to research renal functions of patients diagnosed with hypertension and type 2 diabetes mellitus in addition to hypertension and to evaluate by comparing the effects of these diseases on kidney. Method: The 85 hypertension patients and 85 diabetes mellitus and hypertension patients, totally 170 patients, between 35-70 ages involved in this study by retrospectively screening the archive files of internal medicine and diabetes outpatient clinics. Clinical findings and demographic features have been noted by screening the patient files in both groups. Results: The rate of albuminuria was significantly higher in diabetes mellitus and hypertension group $(30.6 \%)$ than hypertension group $(16.5 \%)(\mathrm{p}=0.047)$. In terms of the prevalence of cases whose glomerular filtration rate $<60 \mathrm{~mL} / \mathrm{min} / 1.73 \mathrm{~m} 2$, there was no significant difference between HT group (2.4\%) and diabetes mellitus and hypertension group (5.9\%), $(\mathrm{p}=0.44)$. Conclusion: Type 2 diabetes mellitus; increases albuminuria in patients with hypertension. This situation may be predictor of rapid progression to renal failure.

Keywords: Hypertension, type 2 Diabetes Mellitus, kidney disease.

Received / Geliş tarihi: 28.01.2017, Accepted / Kabul tarihi: 22.04.2017

${ }^{1}$ Dicle Üniversitesi Tıp Fakültesi Aile Hekimliği Anabilim Dalı

*Address for Correspondence / Yazışma Adrsi: Hamza Aslanhan, Dicle Üniversitesi Tıp Fakültesi Aile Hekimliği Anabilim Dalı, Diyarbakır-TÜRKIYYE E-mail: haslan21@gmail.com

Aslanhan H, Yılmaz A. Hipertansif Hastalarda Tip II Diabetes Mellitusun Renal Parametreler Üzerine Etkisi: Karşılaştırmalı Bir Çalışma.TJFMPC, 2017;11(2): 88-92

DOI: $10.21763 /$ tjfmpc.317779 


\section{GíRiş}

Hipertansiyon (HT), önemli bir halk sağlığ1 sorunudur. Dünyada, yaklaşık 1 milyardan fazla kişide HT görülmektedir ${ }^{1}$. Türkiye'de, HT prevalansı her geçen gün artmaktadır ${ }^{2}$.

Diabetes mellitus (DM), kronik hiperglisemi ile seyreden, etyolojisi değişik bir dizi metabolik bozukluğu ifade eder. İnsülin sekresyonunda azalma, ya da insülin etkisinin yetersiz olması ve bazen de her ikisinin kusurlarından kaynaklanan karbonhidrat, protein ve yağ metabolizması bozuklukları, kronik hiperglisemiye yol açar. Tip 2 DM, diyabetin en yaygın formudur, tüm diyabet hastalarının \%80-90 gibi büyük bir kısmını oluşturur ${ }^{3}$.

Tüm dünyada, diyabetli hastaların \%65'inin ölüm nedeni kardiyo vasküler hastalıklardır. Çünkü diyabetli kișilerde, kalp hastalığı nedeniyle ölüm hızı, normal kişilere göre 24 kat fazladır ${ }^{4}$. DM ve HT tespit edildiği anda, organ hasarı bulguları da gelişmiş olabilir. Diyabetik nefropati, ABD ve Avrupa'da son dönem böbrek yetersizliğinin önde gelen nedeni olarak karşımıza çıkmaktadır ${ }^{5}$. Ülkemizde, Türk Nefroloji Derneği kayıtlarına göre, yeni tanı konmuş son dönem böbrek yetmezliği olan hastaların \%25,3'nü diyabetliler oluşturmaktadır ${ }^{6}$.

Diyabetik nefropati, idrarla atılan protein miktarında artış ile ilişkilidir. Proteinürideki artış, sadece nefropatinin gelişeceğinin habercisi olmakla kalmayıp, aynı zamanda diyabetik hastaların kardiyovasküler hastalık nedeni ile erken dönemde ölme olasılıklarını güçlü bir biçimde ortaya koyar ${ }^{7}$.

Diyabet ve hipertansiyon bir arada bulunduğu zaman, kişiyi ani kardiyak ölüm, koroner kalp hastalığı, konjestif kalp yetersizliği, serebrovasküler hastalık ve periferik damar hastalığ 1 gelişmesi yönünden, çok daha büyük bir tehlikeyle karşı karşıya bırakır. Tip 2 diyabette uzun dönemde morbidite artar, mortalite yükselir ${ }^{8}$. Diyabetin, makrovasküler komplikasyonları içinde, kardiyovasküler hastalıklar özellikle kadınlarda olmak üzere, her iki cinsiyette de önde gelen ölüm nedenidir. Hipertansiyon ve diabetes mellitus s1k görülmeleri, ciddi morbidite ve mortaliteye sahip olmaları, ekonomik anlamda sağlık giderlerini arttırmaları nedeniyle önemli epidemik sorun haline gelmişlerdir.

Bu çalışmamızda, HT hastaları ile HT'a ek olarak Tip 2 DM'si olan hastaların, renal fonksiyonlarını incelemeyi ve bu hastalıkların böbrek üzerindeki etkilerini karşılaştırarak değerlendirmeyi amaçladık.

\section{GEREÇ VE YÖNTEM}

Bu çalışmamızda, Mart 2012 ile Haziran 2012 tarihleri arasında, İstanbul Eğitim Araştırma Hastanesi Dahiliye ve Diyabet polikliniklerinde, HT ve HT'a ek Tip 2 DM tanıları ile takip edilen hastaların arşiv dosyaları retrospektif olarak tarandı. Dahil edilme kriterlerini karşılayan toplam 300 dosyadan, basit tesadüfi örnekleme yöntemi ile 35 70 yaşları arasında 85 HT, 85 HT + Tip2 DM tanıları almış, toplam 170 adet hasta çalışmaya dahil edildi.

Çalışmaya dahil edilmede, Diyabet tanısı için ADA (Amerikan Diyabet Birliği) kriterleri ${ }^{9}$ HT için, sistolik kan basıncının $\geq 140 \mathrm{mmHg}$ (diyabetiklerde $\geq 130$ ) ve/veya diyastolik kan basıncının $\geq 90 \mathrm{mmHg}$ (diyabetiklerde $\geq 80$ ) olmas1 kriter olarak kullanıld $1^{15,16}$. Hasta dosyalarında kayıtlı ölçümler esas alındı. Takip edilmekte olan hastaların dosyalarından; hastaların ilk başvurudaki ve son kontrollerindeki klinik bulgular, yaş, cinsiyet, tam idrar tahlili, serum üre-kreatinin değerleri kaydedildi. Üre (mg/dL, ref aralığı:20-40); üreaz kullanılarak enzimatik yöntemlerle, kreatinin $(\mathrm{mEq} / \mathrm{L}$, ref aralığı:0,5-1,2); modifiye jaffe metoduyla $^{10}$ ve albuminüri; immunotürbidimetrik yöntemle ${ }^{11}$ Siemens Advia 2400 oto analizörü ile çalışıldı. Spot idrarda, $300 \mathrm{mg} / \mathrm{dl}$ üzerindeki değerler albüminüri olarak değerlendirildi ${ }^{3,12}$.

$\begin{array}{llr}\begin{array}{l}\text { Glomerüler } \\ \text { filtrasyon hızı }\end{array} & \begin{array}{r}\text { (GFR) } \\ \text { hesaplamasında }\end{array} \\ \text { Cockroft-Gault } & \text { formülü }\end{array}$
kullanıld $1^{13}$ :

GFR = (140 - yaş) $x$ Vücut ağırlı̆ğ $(\mathrm{kg}) /$ (serum kreatinini x 72)* (*Kadın hastalarda çıkan sonuç 0.85 ile çarpıldı.)

GFR<60 mL/dk/1.73 $\mathrm{m}^{2}$ olan hastalarda, orta-ciddi böbrek hastalığı olduğu kabul edildi ${ }^{14}$.

Tip 1 diyabet hastaları, renal replasman tedavisi alanlar, üriner sistem infeksiyonu bulunanlar, akut hastalığı bulunanlar, gebelik ve laktasyon döneminde olan hastalar ve karaciğer sirozu tanısı almış olan hastalar çalışmaya alınmadı.

\section{Istatistiksel analiz:}

Çalışmamızda, elde edilen sonuçların istatistiksel analizleri SPSS 18 paket programı ile yapıldı. Karşılaştırmalarda bağımsı gruplarda $\mathrm{t}$ testi (student t) ve ki kare testleri kullanıld1, $\mathrm{p}<0,05$ anlamlı kabul edildi. 


\section{BULGULAR}

Çalışmamızda değerlendirilen, 170 hastanın \%30'u erkek (n=51), \%70'i (n=119) kadınd. Gruplar arasında cinsiyet açısından fark yoktu $\left(\mathrm{X}^{2}=0,699\right.$; $\mathrm{p}=0,403)$. Yaş ortalamaları, kadınlarda 58,3 $\pm 7,1$, erkeklerde 57,6 $\pm 7,5$ idi. Yaş ortalamaları açısından HT grubu $(57,6 \pm 7,5)$ ile HT+Tip 2 DM grubu $(58,3 \pm 7,2)$ arasinda anlamlı bir fark yoktu $(\mathrm{t}=-0,638$, $\mathrm{p}=0,525)$ (Tablo 1).
Üre, kreatinin, GFR açısından karşılaştırıldığında, HT grubu ile HT+ Tip 2 DM grubu arasında istatistiksel olarak anlamlı fark yoktu (Tablo 2).

Hastalar, albuminüri yönünden incelendiğinde, HT+Tip2 DM grubunda albüminürisi olanların oranı $(\% 30,6)$, HT grubunda albüminürisi olanların oranından $(\% 16,7)$ anlamlı olarak daha yüksekti $\left(\mathrm{X}^{2}=3,94 ; \mathrm{p}=0,047\right)$ (Tablo 3$)$.

Tablo 1. Grupların cinsiyet ve yaş yönünden karşılaştırılması

\begin{tabular}{|c|c|c|c|c|c|}
\hline & & DM+HT & HT & Test sabiti & p \\
\hline \multirow{2}{*}{ Cinsiyet } & Kadın & $57(\% 67,1)$ & $62(\% 72,9)$ & \multirow{2}{*}{$\mathrm{X}^{2}=0,699$} & 0,403 \\
\cline { 2 - 5 } & Erkek & $28(\% 32,9)$ & $23(\% 27,1)$ & & 0,525 \\
\hline Yaş & & $58,33 \pm 7,17$ & $57,61 \pm 7,50$ & $\mathrm{t}=-0,638$ & \\
\hline
\end{tabular}

Tablo 2. Grupların renal parametreler yönünden karşılaştırılması

\begin{tabular}{|c|c|c|c|c|c|}
\hline & & $\begin{array}{c}\text { DM+HT } \\
\text { N }(\%)\end{array}$ & $\begin{array}{c}\text { HT } \\
\mathrm{N}(\%)\end{array}$ & Test sabiti & $\mathbf{p}$ \\
\hline \multirow[b]{2}{*}{ Üre } & Normal (20-39 mg/Dl) & $74(87,1)$ & $76(89,4)$ & \multirow[t]{2}{*}{$t=0,226$} & \multirow[t]{2}{*}{0,634} \\
\hline & Yüksek (>40 mg/Dl) & $11(12,9)$ & $9(10,6)$ & & \\
\hline \multirow[t]{2}{*}{ Kreatinin } & Normal $(0,5-1,1 \mathrm{mEq} / \mathrm{L})$ & $79(92,9)$ & $83(97,6)$ & \multirow[t]{2}{*}{$\mathrm{t}=1,181$} & \multirow[t]{2}{*}{0,277} \\
\hline & Yüksek (>1,2 mEq/L) & $6(7,1)$ & $2(2,4)$ & & \\
\hline \multirow[t]{2}{*}{ GFR } & $\geq 60 \mathrm{~mL} / \mathrm{dk} / 1.73 / \mathrm{m}^{2}$ & $80(94,1)$ & $83(97,6)$ & \multirow[t]{2}{*}{$t=0,596$} & \multirow[t]{2}{*}{0,440} \\
\hline & $<60 \mathrm{~mL} / \mathrm{dk} / 1.73 \mathrm{~m}^{2}$ & $5(5,9)$ & $2(2,4)$ & & \\
\hline
\end{tabular}

GFR: Glomerüler Filtrasyon Hızı

Tablo 3. Grupların albuminüri yönünden karşılaştırılması

\begin{tabular}{|l|c|c|c|c|}
\hline & HT & DM+HT & Test sabiti & p \\
\hline Normoalbuminüri & N (\%) & N (\%) & \\
\hline Albuminüri & $14(83,5)$ & $59(69,4)$ & \multirow{2}{*}{$\mathrm{X}^{2}=3,94$} & \multirow{2}{*}{0,047} \\
\hline
\end{tabular}




\section{TARTIŞMA}

Çalışmamızda, hipertansif hastalar ile diabetik hipertansif hastaların yaş, cinsiyet, üre, kreatinin, GFR değerleri yönünden aralarında anlamlı fark olmayıp, albuminüri yönünden diabetik hipertansif hasta grubunun anlamlı yüksek sonuçlara sahip olduğu görüldü.

Tip 2 DM ve HT, toplumda yaygın olarak görülen iki hastalık grubudur. HT ve Tip 2 DM pek çok sistemi etkileyerek, mortalite ve morbiditeyi arttırmaktadır. $\mathrm{Bu}$ hastalıklara bağlı nefropati, kardiyovasküler hastalık, retinopati gibi kronik komplikasyonlar meydana gelmektedir. Kronik komplikasyonlar hastanın yaşam süresinin kısalması, yaşam kalitesinde bozulma, iş gücü kaybı ve tedavi maliyetlerinde artışa neden olmaktadır.

İspanya'da çok merkezli yapılan RICARHD çalışmasında, 55 yaş üstü HT + Tip 2 DM tanılı 2339 hastada, GFR $<60 \mathrm{~mL} / \mathrm{dk} / 1,73 \mathrm{~m}^{2}$ oran1 $\% 45,1$ olarak bulunmuştur ${ }^{17}$. İspanya'da, 1723 birinci basamak hekimi tarafından, çok merkezli yapılan MAGAL çalışmasıyla HT + Tip 2 DM tanılı hastalarda, GFR $<60 \mathrm{~mL} / \mathrm{dk} / 1,73 \mathrm{~m}^{2}$ oran1 $\% 21,8$ olarak bulunmuştur ${ }^{18}$. Yine dünya çapında, 26 ülkeden 1750 merkezin katılımı ile yürütülen çokuluslu i-SEARCH çalışmasının, Türkiye kolunu temsil eden gözlemsel, kesitsel ve çok merkezli çalışmaya, Türkiye'den toplam 1926 hipertansiyon hastası alınmış, hastaların \%35,5'inde tip 2 ağırlıklı olmak üzere, diyabet saptanan bu çalışmada GFR $<60 \mathrm{~mL} / \mathrm{dk} / 1,73 \mathrm{~m}^{2}$ oranı ise \%11 olarak bulunmuştur ${ }^{19}$. Bizim çalışmamızda ise bu oran $\% 5,9$ olarak bulunmuştur. $\mathrm{Bu}$ değişik sonuçlar, bizim hasta sayımızın az olmasından ve medikal takiplerin görece iyi olmasından (endokrinolog ve nefrologların bulunduğu ekibin varlığı, hem medikal tedavi, hem de diyet ve egzersiz önerilerini dikkate alan uyumlu hasta profili, dosya takiplerinin ve kayıtlarının düzenli yapılması vb.) kaynaklanmış olabilir.

Çöl ve arkadaşlarının yaptığı çalışmada, albüminuri oranı HT olan hastalarda \%20,1 iken, HT+ Tip 2 DM olanlarda ise \%25,8 dir ${ }^{20}$. Rius ve arkadaşlarının, 73 normotansif, 73 hipertansif ve tip 2 DM'linin renal fonksiyonlarını karşılaştırdıkları çalışmada, HT + Tip 2 DM tanılı hastalarda albuminuri oranı \%34,2 olarak bulunmuştur ${ }^{21}$. Carmona ve arkadaşlarının, Portekiz'de 97 HT + Tip 2 DM tanılı hastada yaptıkları çalışmada mikroalbuminuri oranı $\% 35$ olarak bulunmuştur ${ }^{22}$. Bizim çalışmamızda ise, sadece hipertansif hastalarda albuminuri oran $1 \% 16,5$ bulunurken, Tip 2 DM'nin eşlik ettiği hipertansif hastalarda bu oran \%30,6 olarak bulunmuştur. Bulgularımızın, yukarıdaki çalışmalarla uyumlu olduğu görülmüştür. Ancak daha geniş ölçekli çalışmalarda oranların daha yüksek olduğu dikkati çekmektedir.
İspanya'da, 1723 birinci basamak hekimi tarafından çok merkezli yapılan MAGAL çalışmasında, hipertansiyonu ve diyabeti olan 6227 hasta analiz edilmiş, sadece hipertansiyonu olan 1128 hastada albuminuri oranı \%39,7 bulunurken, hipertansiyona Tip 2 DM'un eklendiği 2598 hastada ise albuminuri oranı \%65,6 olarak bulunmuştur ${ }^{23}$. Yine İspanya'da, çok merkezli yapılan RICARHD çalışmasında 55 yaş üstü HT + Tip 2 DM tanılı 2339 hastada albuminuri oranı \%58,7 olarak bulunmuştur ${ }^{17}$. Bu durum, örneklem grubunun özelliklerinden ve sayısından kaynaklanmış olabilir.

Literatürde olduğu gibi, bizim çalışmamızda da albuminuri oranı, Tip 2 diabetes mellitus ve hipertansiyon hasta grubunda, sadece hipertansiyon hasta grubuna göre istatistiksel olarak anlamlı derecede daha yüksek bulunmuştur. Hipertansiyon hastalarının beraberinde Tip 2 DM olmasının, renal yetmezliğin daha erken ve sik görülmesine yol açabileceğini göstermektedir.

\section{Çalışmanın kısıtlılıkları:}

Hasta sayımız, incelenen dosya inceleme süre aralığının dar oluşundan dolayı düşüktür. Hasta gruplarını oluştururken, kriterlerimize uygun izole hipertansiyon hastalarının belirlenmesinde güçlük yaşanmıştır. GFR'si ciddi düzeyde bozuk hastaların, dahiliye ve diyabet polikliniklerinde takip edilmiyor olabilmeleri çalışmamızın diğer bir kısıtlılığıdır. Yapılacak çalışmaların, geniş vaka serileri ve inceleme aralığı ile farklı kliniklerde yapılması önerilir.

\section{SONUÇ}

Tip 2 diabetes mellitus; hipertansiyon hastalarında albüminüriyi arttırmaktadır. $\mathrm{Bu}$ iki hastalığın birlikteliğinde, albuminüri takibinin daha s1k1 yapılması ve uygun girişimlerde bulunulması böbrek yetmezliğine gidişi geciktirmede katkı sağlayabilir.

\section{ÇIKAR ÇATIŞMASI}

Yazarlar bu yazının hazırlanması ve yayınlanması aşamasında herhangi bir çıkar çatışması olmadığını beyan etmişlerdir.

\section{KAYNAKLAR}

1. Kotseva K, Wood D, De Backer G, De Bacquer D, Pyörälä K, Keil U, et al. Cardiovascular prevention guidelines in daily practice: a comparison of EUROASPIRE I, II, and III surveys in eight European countries. The Lancet 2009;373(9667):929-40.

2. Sengul S, Akpolat T, Erdem Y, Derici U, Arici $\mathrm{M}$, Sindel S, et al. Changes in hypertension 
prevalence, awareness, treatment, and control rates in Turkey from 2003 to 2012. Journal of hypertension 2016;34(6):1208.

3. Yenigün $M$, Altuntaş Y. Her yönüyle diabetes mellitus. Nobel Tip 2001;(2):219.

4. Control CfD, Prevention. National diabetes fact sheet: national estimates and general information on diabetes and prediabetes in the United States, 2011. Atlanta, GA: US Department of Health and Human Services, Centers for Disease Control and Prevention 2011;201(1).

5. Nan H, Dong Y, Gao W, Tuomilehto J, Qiao Q. Diabetes associated with a low serum uric acid level in a general Chinese population. Diabetes research and clinical practice 2007;76(1):68-74.

6. Büyükdevrim A, Büyükbeşe M, Davutoğlu MT. Diabetik Nefropati. Turgut Yayıncılık AŞ; 2005. p.8-11.

7. Klausen K, Parving HH, Scharling H, Jensen J. The association between metabolic syndrome, microalbuminuria and impaired renal function in the general population: impact on cardiovascular disease and mortality. Journal of İnternal Medicine 2007;262(4):470-8.

8. Yılmaz A, Kılınç F, Usman MG, Sucaklı MH, Tanriverdi HM, Aslanhan $\mathrm{H}$, et al. The prevalence of diabetes mellitus, dysglycaemia and factors that affect them in public employees of Kahramanmaras. Turkish Journal of Family Medicine \& Primary Care 2015;9(3):99-103.

9. Satman İ, Yılmaz C. Glisemik bozukluklarda tanı sınıflama ve tedavi. Türkiye Endokrinoloji ve Metabolizma Derneği, Diabetes Mellitus ve Komplikasyonlarının Tanı, Tedavi ve İzlemi Kılavuzu. Müka Yayıncılık. 2008; 3:11-3.

10. Aydınbelge B, Kılınç A, Diri B, Duranay M, Saydam G, Yücel D. Gerçek kreatinin ölçümü için geliştirilen kreatinin ölçüm yöntemlerinin karşılaştırılması. Turk J Biochem 2011;36(4):356-61.

11. Kocabaş RN, Başol G. Proteinüri ve laboratuvar değerlendirmesi. Türk Klinik Biyokimya Derg 2006;4(3):133-45.

12. Parving $\mathrm{HH}$, Chaturvedi N, Viberti G, Mogensen CE. Does microalbuminuria predict diabetic nephropathy? Diabetes Care 2002;25(2):406-7.

13. Michels WM, Grootendorst DC, Verduijn M, Elliott EG, Dekker FW, Krediet RT. Performance of the Cockcroft-Gault, MDRD, and new CKD-EPI formulas in relation to GFR, age, and body size. Clinical Journal of The American Society of Nephrology 2010;5(6):1003-9.

14. Lee GS. Retarding the progression of diabetic nephropathy in type 2 diabetes mellitus: focus on hypertension and proteinuria. Annals of The Academy of Medicine, Singapore 2005;34(1):24-30.
15. Barçın C. What has changed with the new European Society of Cardiology/European Society of Hypertension guideline? Archives of The Turkish Society of Cardiology 2014;42(1):1-6.

16. Tokgözoğlu L, Kayıkçığlu M, Altay S, Aydoğdu S, Barçın C, Bostan C, et al. EUROASPIRE-IV: Avrupa Kardiyoloji Derneği'nin koroner arter hastalarında yaşam tarzı, risk faktörleri ve tedavi yaklaşımı üzerine çalışması: Türkiye verileri. Turk Kardiyol Dern Ars 2017;45(2).

17. Cea-Calvo L, Conthe P, Gomez-Fernandez P, de Alvaro F, Fernandez-Perez C, investigators R. Target organ damage and cardiovascular complications in patients with hypertension and type 2 diabetes in Spain: a cross-sectional study. Cardiovascular Diabetology 2006; 5:23.

18. Redon J, Morales-Olivas F, Galgo A, Brito MA, Mediavilla J, Marin R, et al. Urinary albumin excretion and glomerular filtration rate across the spectrum of glucose abnormalities in essential hypertension. Journal of the American Society of Nephrology 2006;17(12 Suppl 3):236-45.

19. Kozan Ö, Ozcan E, Sancaktar O, Kabakcı G. The prevalence of microalbuminuria and relevant cardiovascular risk factors in Turkish hypertensive patients. Turk Kardiyol Dern Ars 2011;39(8):635-45.

20. Col M, Ocaktan E, Ozdemir O, Yalcin A, Tuncbilek A. Microalbuminuria: prevalence in hypertensives and diabetics. Acta medica Austriaca 2004;31(1):23-9.

21. Rius F, Pizarro E, Castells I, Salinas I, Sanmartí A, Romero R. Renal function changes in hypertensive patients with non-insulindependent diabetes mellitus. Kidney International Supplement 1996(55).

22. Stekiel TA, S JC, Bosnjak ZJ, Kampine JP, Roman RJ, Stekiel WJ. Reversal of minimum alveolar concentrations of volatile anesthetics by chromosomal substitution. Anesthesiology. 2004;101(3):796-8.

23. Redon J, Morales-Olivas F, Galgo A, Brito MÁ, Mediavilla J, Marín R, et al. Urinary albumin excretion and glomerular filtration rate across the spectrum of glucose abnormalities in essential hypertension. Journal of the American Society of Nephrology 2006;17(12 suppl 3):236-45. 